\title{
Exploring the Teaching Method of Precision Design Course
}

\author{
Qingyue Wei \\ Department of Mechanical Automation Engineering \\ Shanghai University \\ Shanghai, China \\ Weiqy@i.shu.edu.cn \\ Yingzhong Tian \\ Department of Mechanical Automation Engineering \\ Shanghai University \\ Shanghai, China \\ troytian@shu.edu.cn
}

\author{
Ming Li \\ Department of Mechanical Automation Engineering \\ Shanghai University \\ Shanghai, China \\ robotlib@staff.shu.edu.cn \\ Huijuan $\mathrm{Hu}^{*}$ \\ Department of Mechanical Automation Engineering \\ Shanghai University \\ Shanghai, China \\ huhuijuan@shu.edu.cn
}

\begin{abstract}
Geometric accuracy is an important factor in product quality. However, due to the lack of basic technical knowledge, it is difficult for students to grasp the object of precision design and the method of precision control in the actual teaching process. This paper combines ISO's Geometrical Product Specifications and Verification (GPS\&V) standard system to form a set of effective geometric precision design and control practical teaching methods by reorganizing, correlating and reforming related courses and teaching contents.
\end{abstract}

Keywords-Geometric accuracy; GPS\&V; Control method; Practical Teaching

\section{INTRODUCTION}

Geometric quality is an important part of the quality of tangible products. Taking the automobile as an example, according to the statistics of the American authoritative consulting company JD. Power, $42 \%$ of the quality problems in the automotive field are related to the geometric error of the vehicle body [1]. Therefore, the design and control of product precision is a compulsory basic course for college student majoring in machinery.

Product design and control require a good process foundation; otherwise, it is impossible to accurately describe the product application functions and controls on the engineering drawings. At the same time, engineering drawings are a standardized engineering language. How to express the application functions and control requirements of products in a standardized way is another problem that needs to be solved in the teaching process. From the above analysis, we can see that if you need to let students really master this basic course, you must solve the following problems:

1. In the process of teaching the geometric precision design course, it is necessary to synchronize the concept of function and process, that is, it is necessary to adopt the necessary means to enable students to simultaneously understand the functional requirements and control requirements. [2]
2. National/International Standards for Geometrical Product Specifications and Verification (GPS\&V) [3], which are specifications for Geometry Dimension and Tolerance (GD\&T).

3. It is necessary to combine the functional and control requirements to verify the tolerance design results and the machining results of the components. [4]This involves the dimensional verification after the initial completion of the GD\&T engineering drawings and the geometric accuracy measurement for the physical objects. Complete process and method architecture for the process of geometric function realization and precision machining control. [5-6]

From the above analysis, it is necessary to make necessary adjustments and treatments to the existing curriculum system, teaching methods, and the connection between multiple courses.

In addition, combined with the current concepts and research of advanced manufacturing, it is also necessary to explore the development direction and application methods of precision design courses in the future manufacturing, so that students' acquired knowledge can keep up with the needs of manufacturing development.

\section{THE INTERPRETATION OF MODERN GEOMETRIC PRECISION DESIGN AND CONTROL METHODS}

The general idea of curriculum reform is clear, but what is the specific grasp? In fact, the standard is the crystallization of engineering practice. It embodies practically proven ideas, ideas and practical methods. Therefore, we begin to improve the concept, ideas and capabilities of the teaching team from the learning standards.

Since 1993, ISO has started to comprehensively discuss and standardize the function realization and control methods of geometric products. After 25 years of hard work, a complete standard system consisting of more than 150 standards has been formed that can face the transformation of the 
manufacturing industry. The national/international standard of Geometrical Product Specifications and Verification (GPS\&V) has its main features.

1. Using the principle of duality, the product functions and control requirements are associated with the specification of the engineering drawings. This is actually a virtual and real method. The final result is a digital twin (Digit Twin).

2. A risk-based thinking approach is presented. Verification is fully embedded in the design, control, and manufacturing processes. The main verification areas are:

1) GD\&T design verification: including the standardization of the pattern and the GD\&T design rationality based on the manufacturing capability characteristics, the ultimate goal is to give the GD\&T engineering bottom line.

2) Verification of manufacturing capability: Although this part of the requirement is not directly included in the GPS\&V standard system, the ISO standard itself is a larger and complete system. The verification of manufacturing capability is indispensable for geometric precision process control. It evaluates and controls the single, transient and steady-state capabilities of the manufacturing unit and system. The technical indicators used are Cpk, Cmk, Ppk, etc.

3) Verification of measurement system capability: This part is achieved by estimating the uncertainty of measurement, including the measurement uncertainty optimization process (PUMA process), the process of the tester and the tester expressing the measurement uncertainty, etc.

3. Integration of information technology: Through the standardized functions and control requirements, the computer can understand the labeling content of the drawings, so that the subsequent drawings can be automatically interpreted and transmitted. Especially with the development of Model Based Design (MBD) technology, all annotations are integrated into one model (also known as data packets) through PMI and 3D annotation methods, which will completely reform GD\&T and Application method of engineering drawings.

As can be seen from the above discussion, the GPS\&V standard covers all the concepts, ideas, methods and tools required for geometric precision design and assurance. It is also the theoretical basis and core structure for the reform of engineering teaching curriculum in combination with the requirements of new engineering construction.

\section{Discussion On The Practice-BAsed TeAching METHOD}

In the reform of engineering teaching curriculum, it is necessary to realize that our existing teaching system has a big gap with these concepts, ideas, methods and tools contained in the GPS \& V standard system. Therefore, it is necessary to re-create the teaching system according to the most advanced technology system.

From the perspective of the accuracy and design of colleges and universities today, it is difficult to fully reflect GPS\&V. The first thing that needs to be solved is the overall goal and requirements.

The existing GPS\&V standard system is faced with industrial scenes. It is impossible to fully teach the system. It is necessary to combine the engineering education reform and rationally apply the combination of theory, experiment and practice to construct the curriculum structure from the engineering consciousness, engineering knowledge, engineering system and engineering technology.

Due to the large amount of content involved in GPS\&V, the current precision design time is not enough. However, it can be found that many of the contents involved in GPS\&V are also covered in other courses, including: engineering drawing, mechanical design, mechanical manufacturing process, CNC machine tools, precision measurement, quality control and other courses. If we can integrate the contents of GPS\&V from the curriculum system and carry out systematic curriculum reform, it is possible to systematically transfer the concepts, ideas, methods and tools of GPS\&V to students.

Combined with the entire engineering teaching curriculum system, we have made the following planning for the content of the relevant curriculum reform and related links:

TABLE I. THE GEOMETRIC PRECISION DESIGN AND CONTROL COURSE ARCHITECTURE BASED ON GPS\&V

\begin{tabular}{|c|c|c|c|}
\hline Course name & Take the content & $\begin{array}{l}\text { Teaching method } \\
\text { Remarks }\end{array}$ & Remarks \\
\hline Engineering Drawing & $\begin{array}{c}\text { Specification of product functionality and manufacturing } \\
\text { process control requirements }\end{array}$ & Theory and Experiment & $2 \mathrm{D}, 3 \mathrm{D}$ \\
\hline Mechanical Design & $\begin{array}{l}\text { Product Functional Requirements and Assembly Relationship } \\
\text { Design }\end{array}$ & Theory & Benchmark/Benchmark System \\
\hline $\begin{array}{c}\text { Mechanical } \\
\text { Manufacturing Process }\end{array}$ & $\begin{array}{l}\text { Product Manufacturing Process Control Requirements and } \\
\text { Methods }\end{array}$ & Theory and Experiment & Error Control \\
\hline CNC machine tools & Manufacturing system accuracy and capability assessment & Theory and Experiment & Cpk, etc. \\
\hline Precision Measurement & Product Inspection and Acceptance Methods & $\begin{array}{l}\text { Theory, Experiments } \\
\text { and Internships }\end{array}$ & Based on physical and virtual standards \\
\hline Quality Control & Product Process Control and Statistical Analysis & Theory and Experiment & SPC \\
\hline $\begin{array}{l}\text { Precision design and } \\
\text { application }\end{array}$ & $\begin{array}{c}\text { Integrate new knowledge and methods based on the original } \\
\text { curriculum and build relationships with other courses }\end{array}$ & Theory and Experiment & $\begin{array}{c}\text { Dimensional tolerance, geometric } \\
\text { tolerance, surface structure }\end{array}$ \\
\hline CAD and application & 3D-based dimensional chain analysis, 3D annotation & Theory and Experiment & $3 \mathrm{D}$ \\
\hline
\end{tabular}


As can be seen from the above table, if these courses are reformed, it will not only reflect the understanding and application of the most advanced GPS\&V concepts, ideas, methods and tools. It will also support the engineering awareness and knowledge system in mechanical engineering. All of this will eventually be incorporated into the content of the course.

\section{Construction OF THE TEACHING System OF THEORETICAL AND PRACTICAL INTERNSHIP COURSES}

Based on the above discussion, we have adjusted, added and systematically configured the specific content of the entire curriculum system to realize the concepts and ideas of GPS\&V We have strengthened the theory and knowledge system by theoretical teaching as well as the application of methods and tools through experimental teaching and related internships. Its specific construction content includes:

1) "Engineering Drawing":Improve the teaching content with the latest international ISO and national GB standards, which involves the ISO/GB Technical Product Document (TPD) standard system, so that students can master the required standard expression method of the geometric products and their accuracy, which is the most basic knowledge and skills that mechanical students must master. At the same time, the existing engineering drawings have gradually been transformed into the form of 3D models. Based on the teaching of $2 \mathrm{D}$ drawings, the course of 3D standard methods is carried out.

2) "Mechanical Design": At present, the mechanical design course is mainly aimed at the ideal workpiece and state development. According to the concept of GPS\&V, the non-ideal state is introduced into the course teaching. The concept of assembly constraints and degrees of freedom as well as the assembly benchmark and benchmark system concept are introduced into the course too. The functional requirements are formed based on actual operating conditions.

3) "Machinery Manufacturing Process": The mechanical manufacturing process involves two aspects, one is the control of the manufacturing process, and the other is the realization of the final function. For this purpose, the following teaching and experimental contents are specially set:

a) Through the assembly of parts and the design of the clamping experiment students can fully understand the impact of the assembly process and assembly sequence on the final function of the components, as well as the impact of the working conditions on the functions, which can provide support for the marking of relevant requirements in the engineering drawings.

b) Through the design of the sub-item precision measurement experiment of the machine tool, the students can fully understand the factors affecting the accuracy of the parts, and provide support for the control and adjustment of the machining precision, especially the relevant control specifications and markings.

4) "CNC Machine Tool" and "Quality Control": Through the design of the machine tool comprehensive precision measurement experiment, students can fully understand the manufacturing system accuracy status, acquisition methods and evaluation methods. They can also combine with statistical analysis tools to understand the impact of steady state process capability Cpk, single Taiwan's ability Cmk, transient process capability Ppk, etc. on manufacturing, and the application of related tools.

5) "Precision Measurement": Measurement is the verification of the final precision and function of the product. It also involves a huge technical system. It is also included in the GPS\&V standard system. Incorporating this course into the curriculum will help students to fully, systematically and truly master GPS\&V knowledge. To this end, the relevant measurement experiments have been redesigned into teaching and experimentation especially the introduction of three-coordinate measurement and inspection experiments. Combined with the application of the CMM application in Shanghai University and ZEISS in Germany, the system is more systematic and comprehensive, allowing students to master the entire system of geometric precision design control.

6) "Geometry Accuracy Design and Application": This article makes necessary enhancements to the original course content, mainly combines with the GPS\&V standard system, focus on the design method of geometric tolerance (shape and position tolerance) on the original content with tolerance coordination as the core. The measurement method, especially in combination with the adjustment of the content related to the above multiple courses, is carried out in this course. At the same time of theoretical teaching, special experiments are set up to realize the integration and construction of engineering consciousness and engineering knowledge and knowledge system.

7) "CAD and Application": In the aspect of dimension calculation, through the introduction of software such as Siemens VSA and C-TOL, a 3D dimension chain-based analysis platform is formed in the CAD system. This is a virtual design verification platform that provides an effective tool for tolerance design rationalization and normative verification, and enables students to actually experience the role of design verification.

From the above summary, through the curriculum reform of the curriculum, two verification cycles are completely formed, one is based on the $3 \mathrm{D}$ tolerance design verification platform, and the other is based on the geometric measurement function and quality verification platform, The measurements here include measurement methods based on physical standards (traditional measurement methods) and virtual standardizers (based on three-coordinate measurement methods). It also includes control of the manufacturing system and manufacturing process. All the knowledge and skills are taught by the system, including theoretical teaching and experimental teaching taught by the system, including theoretical teaching and experimental teaching.

At present, the system teaching method for geometric precision and quality design control has been carried out in an orderly manner in schools and has achieved good results.

\section{CONCLUSION}

Engineering education reform is a systematic project, and it is necessary to abandon the existing system and even the ideas 
and mentality to carry out the necessary reconstruction. The geometric quality of mechanical products involves the whole process from design, process control and curriculum can we achieve the goal. The curriculum reform attempts and achievements achieved in this paper have reference value for the reform of such courses.

\section{REFERENCES}

[1] Li Ming, Yu Jiping. "Status and development of geometric measurement in Industry” 2017 Vol.38 No.12 pp. 2959-2971. (In Chinese)

[2] Yang Shanguo. "Comprehensive Experiment Design of Geometrical Accuracy Design and Measurement” China Educational Technology \&Equipment 2017 No.10 pp.130-132 (In Chinese)
[3] “Geometrical Product Specifications and Verification, GPS\&V” ISO

[4] He Shengming. “A Comparative Study of Cultural Innovation in Teaching Reform and Practice Research of Tolerance Measurement Course” Comparative Study of Cultural Innovation 2018 No.25 pp.99-100. (In Chinese)

[5] He ShengMing, Guo Jingjing. "Teaching Reform and Practice of "Mechanical Design Basis" Course Based on Task-driven" Contemporary Educational Practice and Teaching Research 2015 No.12 pp.169. (In Chinese)

[6] Hu Liangbin, Li Biwen, Tan. "Research and Practice on Teaching Reform of Mechanical Precision Design and Inspection aiming at Cultivating Engineering Ability” Research on Laboratory Work in Colleges and Universities 2015 No.3 pp.20-21. (In Chinese) 